Review Article

\title{
A Philatelic Excursion with Jeff Hunter in Probability and Matrix Theory
}

\author{
George P. H. Styan and Götz Trenkler \\ Received 15 May 2007; Accepted 8 August 2007 \\ Recommended by Paul Cowpertwait
}

We present an excursion with Jeff Hunter, visiting some of his research topics. Specifically, we will present some facts about certain people whose work seems to have influenced Jeff in his scientific career; we illustrate our presentation with postage stamps that have been issued in honour of these people. Our main guide is Hunter's two-volume book entitled Mathematical Techniques of Applied Probability (Academic Press, 1983).

Copyright @ 2007 G. P. H. Styan and G. Trenkler. This is an open access article distributed under the Creative Commons Attribution License, which permits unrestricted use, distribution, and reproduction in any medium, provided the original work is properly cited.

\section{Introduction}

In the following we are going on an excursion with Jeff Hunter, visiting some of his research topics. Specifically, we will present some facts about certain people whose work seems to have influenced Jeff in his scientific career. We illustrate our presentation with postage stamps that have been issued in honour of these people; we know that Jeff collects stamps. Our main guide will be the two-volume book $[1,2]$ by Hunter. (All but one of the postage stamps depicted in this article are identified with their Scott catalog numbers as found in the Scott 2007 Standard Postage Stamp Catalogue [3].)

\section{Bernoulli, Seki, Leibniz and Chebyshev}

One of the first entries of this two-volume treatment of applied probability is "Bernoulli trial” [1, page 10]: “... a sequence of independent trials is called a sequence of Bernoulli trials." A Bernoulli trial is an experiment whose outcome is random and can be either "success" and "failure" [4]. 

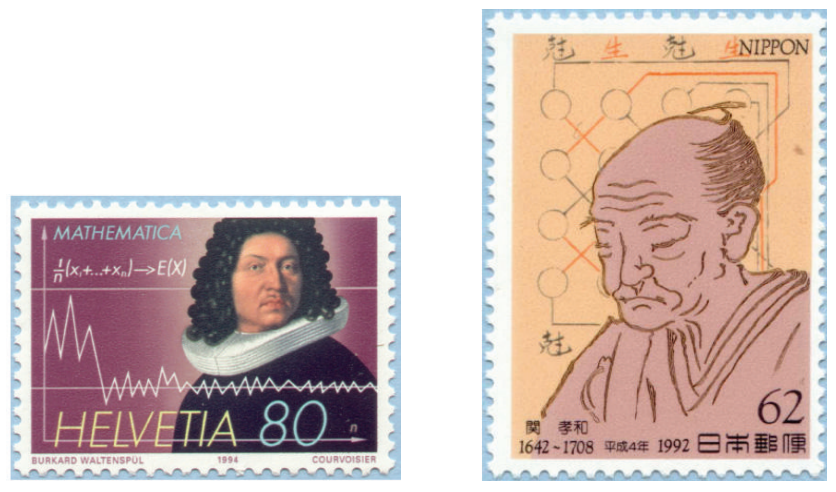

Figure 2.1. (Left panel) Jacob Bernoulli I: Switzerland 1994 (Scott 939); (right panel) Takakazu Seki Kôwa: Japan 1992 (Scott 2147).

The eldest of four brothers, Jacob Bernoulli I (also known as James Bernoulli; first name in German: Jakob, in French: Jacques) lived from 1654 to 1705, mainly in Switzerland. He is one of eight prominent mathematicians in the Bernoulli family [4] and is famous for his Ars Conjectandi [5] (published posthumously in 1713), a ground-breaking work on probability theory, and for his research concerning the law of large numbers, see Figure 2.1 (left panel).

The Bernoulli numbers $B_{k}(k=0,1,2, \ldots)$ are a sequence of signed rational numbers that are implicitly defined by the identity

$$
\frac{x}{e^{x}-1}=\sum_{k=0}^{\infty} \frac{B_{k} x^{k}}{k !} \text {. }
$$

Actually, the Japanese mathematician Takakazu Seki Kôwa (1642-1708) discovered these numbers before Jacob Bernoulli I. Seki also discovered determinants before Leibniz, see, for example, [6-8].

Gottfried Wilhelm von Leibniz (the surname "Leibniz" is sometimes written as "Leibnitz" [6]) (1646-1716) was a German polymath "of remarkable breadth of knowledge, who made original contributions to optics, mechanics, statistics, logic, and probability theory. He conceived the idea of calculating machines and of a universal language. He wrote on history, law, and political theory" [9]; see also [6].

The postage stamp from St. Vincent (in Figure 2.2) was issued for the "750th Anniversary of Hannover: Gottfried Wilhelm Leibniz. Head librarian for the electors of Hannover \& co-inventor of calculus."

The notion of "Markov chain" is already mentioned by Jeff Hunter in [1], but the main theory of Markov chains in discrete time is developed only in [2]. The early research of Andrey Andreyevich Markov (1856-1922) was much influenced by Pafnuty Lvovich Chebyshev (his surname is transliterated in various other ways, for example, Chebychev, Chebyshov, Tchebycheff, or Tschebyscheff $[10,11])(1821-1894)$, see Figure 2.2 (right panel). Chebyshev is probably best known for his inequality, also known as 

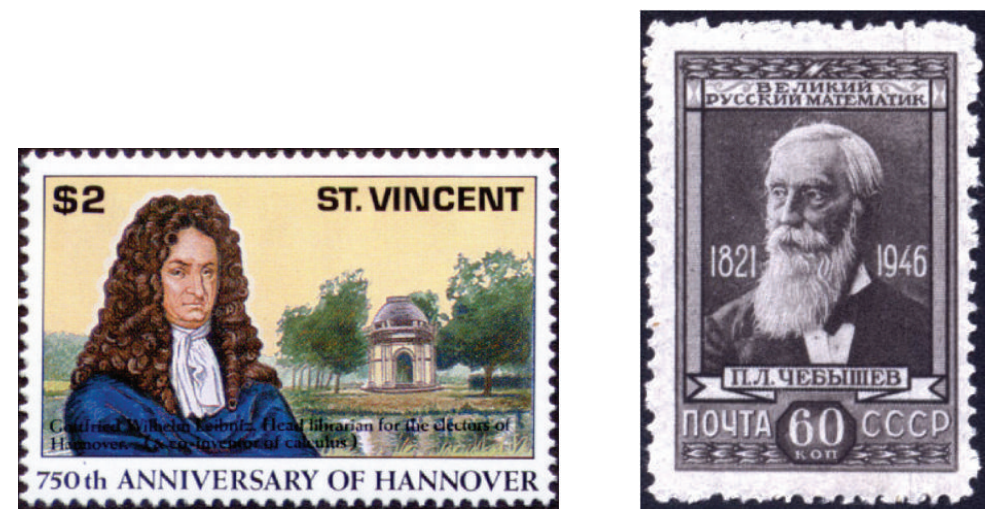

Figure 2.2. (Left panel) Gottfried W. von Leibniz: St. Vincent 1991 (Scott 1557); (right panel) Pafnuty Lvovich Chebyshev: USSR 1946 (Scott 1051).

the Bienaymé-Chebyshev inequality:

$$
\operatorname{Prob}(|X-\mu| \geq k \sigma) \leq \frac{1}{k^{2}}
$$

where $X$ has expected value $\mu$ and variance $\sigma^{2}$, and $k$ is any positive real number. We have not found a postage stamp that honours either Markov or the statistician Irenée-Jules Bienaymé (1796-1878), who proved (2.2) some years before Chebyshev, see, for example, Heyde and Seneta [12, page 132].

\section{Wiener, Brownian Motion, Gauss, Laplace, Abel}

Andrey Andreyevich Markov introduced the concept of a Markov chain as a working model for the study of dependent random variables. Brownian motion is a very good example of a continuous Markov process and is often called a Wiener process; Norbert Wiener (1894-1964) "was an American theoretical and applied mathematician, who is perhaps best known as the founder of cybernetics" [4].

Brownian motion, which is named after the botanist Robert Brown (1773-1858), "is either the random movement of particles suspended in a fluid or the mathematical model used to describe such random movements" [4].

A graph of Brownian motion is shown on a postage stamp (in Figure 3.1 (right panel) right-hand side, center) from Czechoslovakia. This stamp was issued in celebration of the 125th anniversary of the Union of Czechoslovakian Mathematicians and Physicists. Shown on the stamp is "geographical measurement from A. M. Malletta's book (we have not been able to further identify this book), 1672, earth fold and Brownian motion diagrams" [3, volume 2, page 714].

We observe, however, that Jeff Hunter's research interests focus mainly on discrete models. But even in discrete models, continuous distributions play a major role (see, e.g., volume 1, where the distribution of the number of recurrent events is shown to be 
4 Journal of Applied Mathematics and Decision Sciences
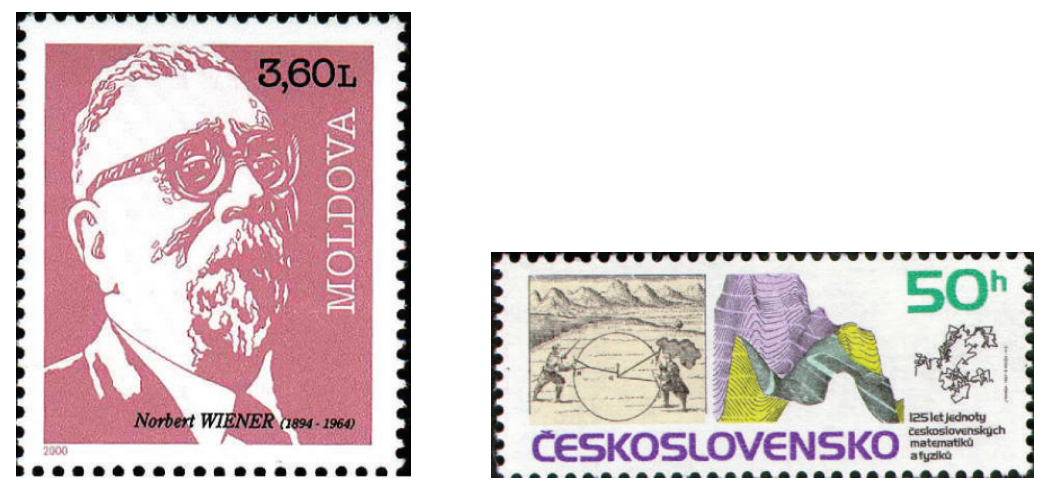

Figure 3.1. (Left panel) Norbert Wiener: Moldova 2000 (Scott 348); (right panel) Brownian motion: Czechoslovakia 1987 (Scott 2665).
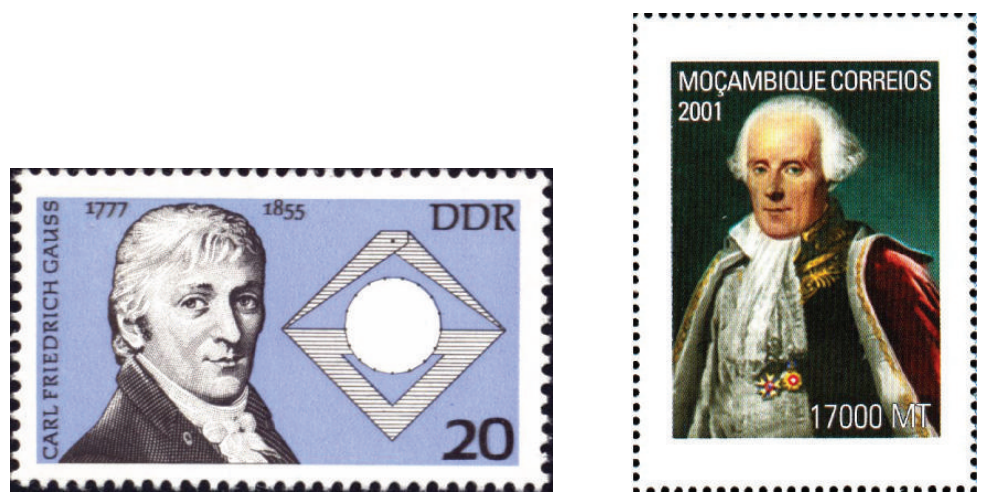

Figure 3.2. (Left panel) Carl Friedrich Gauss: German Democratic Republic 1977 (Scott 1811); (right panel) Pierre-Simon Laplace: Mozambique 2001 (Scott seemingly unlisted (we could not find this stamp listed in the Scott 2007 Standard Postage Stamp Catalogue [3])).

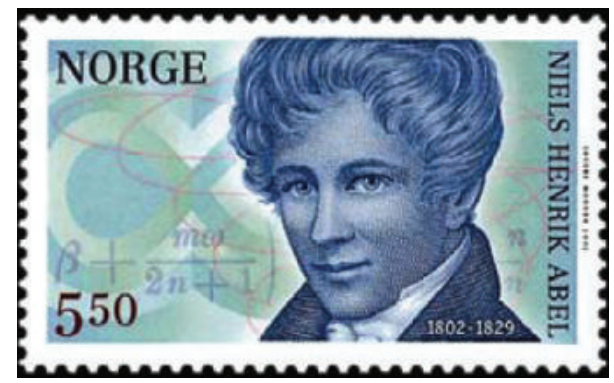

Figure 3.3. Niels Henrik Abel: Norway 2002 (Scott 1333).

approximately normal). The normal distribution is attributed to Carl Friedrich Gauss (the surname "Gauss" is sometimes written as "Gauß”) (1777-1855). 
Beyond mathematics, Gauss did research in astronomy, physics, and geodesy. His principal contributions to statistics are in the theory of least squares estimation, where major work was also done by the mathematician Pierre-Simon, Marquis de Laplace (17491827).

In connection with the behaviour of probability-generating functions and the application of discrete models, convergence problems of infinite series arise. In both volumes of his book, Jeff has to apply Abel's convergence theorem to solve these problems. Niels Henrik Abel (1802-1829) was a Norwegian mathematician, who is best known for proving the impossibility of finding, in closed form, the roots of a polynomial of degree greater than 4. Beyond group theory ("Abelian group"), Abel was especially interested in the theory of functions. In 2001 the government of Norway announced that the bicentennial of Abel's birth (1802) would mark the commencement of a new prize for mathematicians, named after Abel. The Abel Prize is similar to the Nobel Prize which is awarded in Sweden and Norway, but excludes mathematics. Sathamangalam R. Srinivasa Varadhan (born 1940) received the 2007 Abel Prize for his fundamental contributions to probability theory [4].

\section{Euler, Banachiewicz, Penrose triangle, and Hawking}

Matrix theory is a powerful tool which has been widely used by Jeff Hunter in his research papers to further the understanding of the main features of Markov chains. Jeff also devoted one chapter of his book to these techniques. Although Leonhard Euler (1707-1783) did not explicitly use the notion of a matrix (explicitly created only in the mid-19th century), in 1776 Euler created several magic squares, including a $4 \times 4$ magic square [13, page 8$],[14,15]$ which may be represented by the matrix

$$
M=\left(\begin{array}{cccc}
8 & 10 & 15 & 1 \\
11 & 5 & 4 & 14 \\
2 & 16 & 9 & 7 \\
13 & 3 & 6 & 12
\end{array}\right)
$$

Dividing each element of $M$ by 34 yields a doubly stochastic matrix [1, page 127].

When inverting large-scale matrices, Jeff applies results from the theory of partitioned matrices. The latter notion can be traced back to Tadeusz Banachiewicz (1882-1954), who was a Polish astronomer, mathematician, and geodesist, see, for example, $[8,16]$.

The Banachiewicz inversion formula can be stated as

$$
\left(\begin{array}{ll}
P & Q \\
R & S
\end{array}\right)^{-1}=\left(\begin{array}{cc}
P^{-1}+P^{-1} Q T^{-1} R P^{-1} & -P^{-1} Q T^{-1} \\
-T^{-1} R P^{-1} & T^{-1}
\end{array}\right),
$$

where $T=S-R P^{-1} Q$. The matrix $T$ is known as a Schur complement, a concept that has become increasingly important in statistics and applied mathematics in recent years, see, for example, Zhang [17]. In 1925, Banachiewicz invented a theory of "cracovians" (Cracovian calculus), a special kind of matrix algebra, which brought him international recognition. This theory solved several astronomical, geodesic, mechanical, and mathematical problems [4]. 

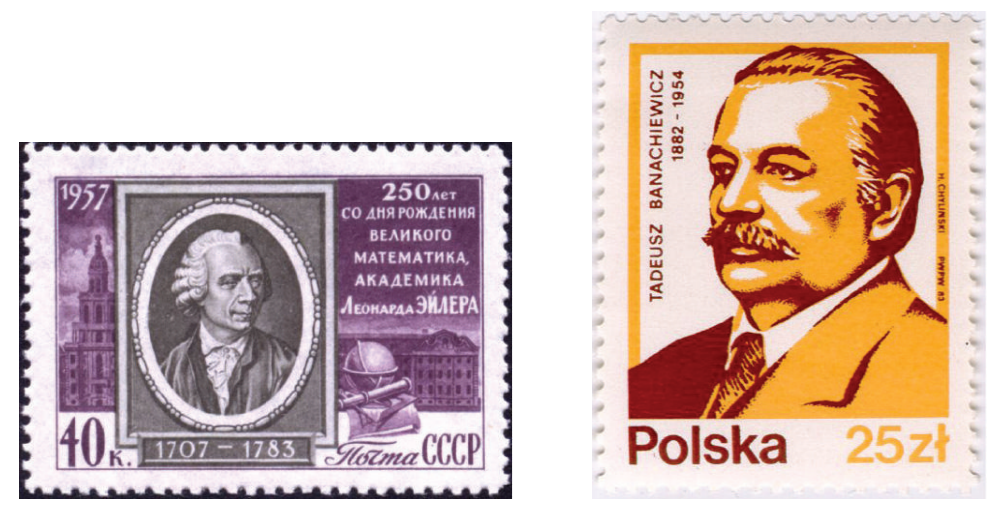

Figure 4.1. (Left panel) Leonhard Euler: USSR 1957 (Scott 1932); (right panel) Tadeusz Banachiewicz: Poland 1983 (Scott 2565).
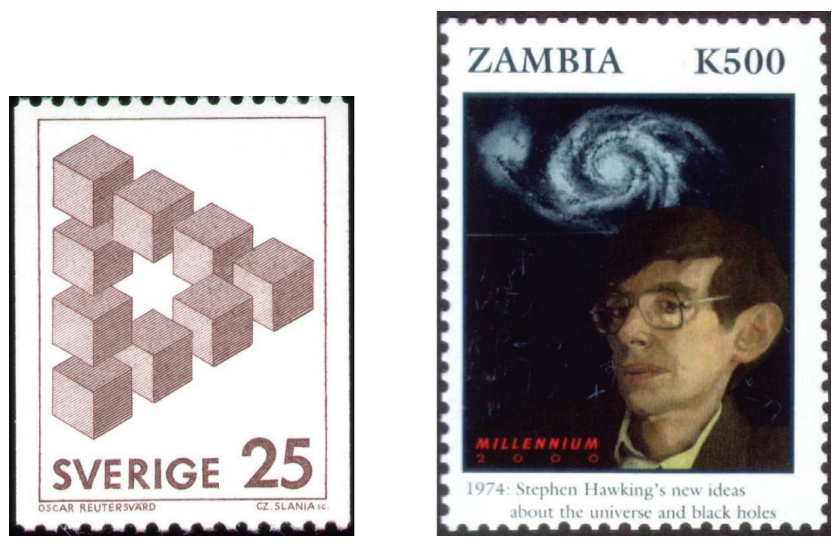

Figure 4.2. (Left panel) Penrose triangle: Sweden 1982 (Scott 1396); (right panel) Stephen Hawking: Zambia 2000 (Scott 856n).

Jeff Hunter has participated in numerous conferences and workshops dedicated to matrix theory and probability, and related fields. In some of these meetings he met the statistician Calyampudi Radhakrishna Rao (born 1920), where both were invited speakers. Rao's tool of a generalized inverse of a matrix was one of Jeff's favourites (see [2] and his research papers, e.g., $[18,19]$ ). (Calyampudi Radhakrishna Rao was the Ph.D. thesis adviser for the 2007 Abel Prize laureate Sathamangalam R. Srinivasa Varadhan, see Section 3.) As is well known, every matrix has a generalized inverse which, however, need not be unique. The Moore-Penrose inverse of a complex matrix $A$ is, however, the unique matrix $G$ satisfying the four equations

$$
A G A=A, \quad G A G=G, \quad A G=(A G)^{*}, \quad G A=(G A)^{*},
$$

where the superscript $*$ denotes conjugate transpose. See, for example, [20, page 40]. 


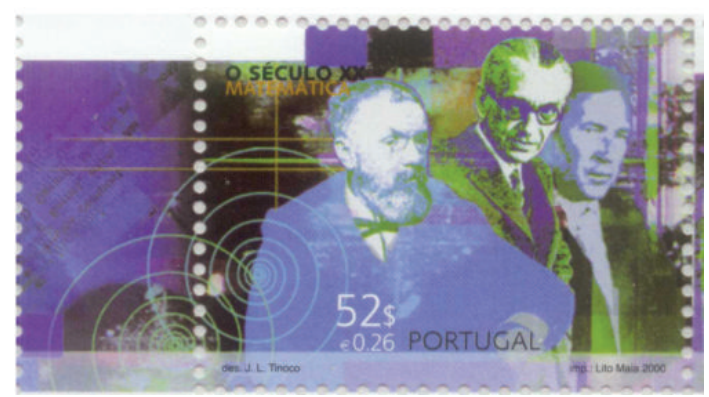

Figure 5.1. Jules Henri Poincaré, Kurt Gödel, and Andrey Nikolaevich Kolmogorov: Portugal 2000 (Scott 2345b).

The Moore-Penrose inverse is named after the mathematician Eliakim Hastings Moore (1862-1932) and the renowned mathematical physicist Sir Roger Penrose (born 1931). It should be mentioned that Penrose, after his research on generalized inverses of matrices in the 1950s, apparently did not pursue his matrix interests any further, but started to work on singularities in the framework of general relativity, together with the famous theoretical physicist Stephen William Hawking (born 1942). The Penrose triangle (Figure 4.2, left panel) is an impossible object first created by the Swedish artist Oscar Reutersvärd (1915-2002) in 1934. Sir Roger Penrose independently devised and popularised it in the 1950s, describing it as "impossibility in its purest form."

\section{Poincaré, Gödel, Kolmogorov, Carroll, and Hua}

Jules Henri Poincaré (1854-1912) "was one of France's greatest mathematicians and theoretical physicists, and a philosopher of science" [4] and in 1886 he was appointed to the Chair of Mathematical Physics and Probability at the Sorbonne. Poincaré is famous for geometric probability. In matrix theory there is the Poincare separation theorem for eigenvalues, see, for example, [21]:

$$
\operatorname{ch}_{n-p+i}(A) \leq \operatorname{ch}_{i}\left(F^{\prime} A F\right) \leq \operatorname{ch}_{i}(A), \quad i=1, \ldots, p \leq n,
$$

where $\mathrm{ch}_{i}$ denotes the $i$ th largest eigenvalue. Here the matrix $A$ is a real symmetric $n \times n$ matrix and $F$ is a real $n \times p$ matrix such that $F^{\prime} F=F F^{\prime}=I_{p}$, the $p \times p$ identity matrix and $F^{\prime}$ is the transpose of $F$.

The postage stamp shown in Figure 5.1 was issued by Portugal as part of a large set in celebration of the 20th century, and includes Kurt Gödel (1906-1978) in addition to Poincaré and Andrey Nikolaevich Kolmogorov (1903-1987).

Kurt Gödel was a mathematician and philosopher. "One of the most significant logicians of all time, Gödel's work has had an immense impact upon scientific and philosophical thinking in the 20th century" [4].

Andrey Nikolaevich Kolmogorov, who is widely considered one of the prominent mathematicians of the 20th century, made major advances in probability theory (as well 

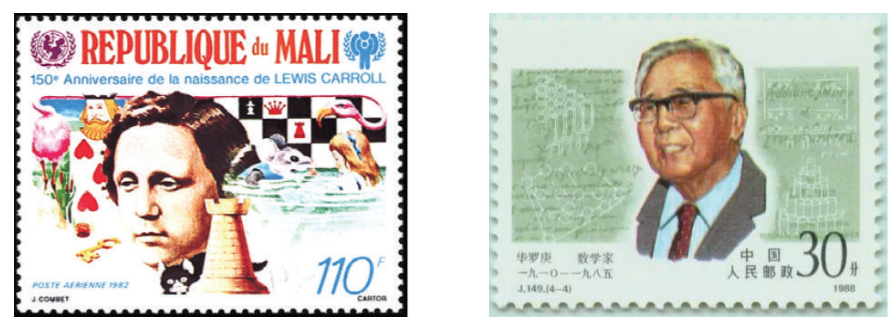

Figure 5.2. (left panel) Lewis Carroll: Mali 1982 (Scott C443); (right panel) Loo-Keng Hua: China 1988 (Scott 2148).

as topology, intuitionistic logic, turbulence, classical mechanics, and computational complexity). Kolmogorov observed that "The theory of probability as a mathematical discipline can and should be developed from axioms in exactly the same way as geometry and algebra" [4].

In connection with matrices, the notion of determinant is indispensable. We have already mentioned that Seki invented determinants a few years before Leibniz. Jeff's book contains a nice collection of rules for determinants.

The first books solely dedicated to determinants, see, for example, [22], were written by the mathematician and physicist William Spottiswoode (1825-1883) and by the author, mathematician, Anglican clergyman, and photographer Rev. Charles Lutwidge Dodgson (1832-1908), who is better known as Lewis Carroll [23]; his books [24, 25] entitled Condensation of Determinants [24] and An Elementary Treatise on Determinants [25] are far less well known than his famous Alice's Adventures in Wonderland (1865) and its sequel Through the Looking-Glass, and What Alice Found There (1871), recently reissued (with an introduction by Martin Gardner) as a single paperback [26]. (The 6-page booklet Condensation of Determinants [24] is just a reprint of an article published in the Proceedings of the Royal Society of London but An Elementary Treatise on Determinants [25] is a 143-page book published by Macmillan, London, 1867.)

Loo-Keng Hua (1910-1985) was a great mathematician and a Chinese legendary hero. (The name "Loo-Keng Hua" is also written as "Hua Loo-keng" [27].) He had little formal education, but made enormous contributions to number theory, algebra, complex analysis, matrix geometry, and applied mathematics" [28, 29]. In particular the inequality

$$
\operatorname{det}\left(I-A^{*} A\right) \cdot \operatorname{det}\left(I-B^{*} B\right) \leq\left|\operatorname{det}\left(I-A^{*} B\right)\right|^{2}
$$

is known as the "Hua determinantal inequality" $[18,30,21]$. Here the matrices $A$ and $B$ are contractive, that is, the singular values all lie in the half-open unit interval $[0,1)$; on the right-hand side of (5.2), the symbol $|\cdot|$ denotes absolute value.

We conclude this little excursion into the world of stamps and mathematics by expressing again our appreciation for Jeff's outstanding research activities, especially in matrix theory. We are sure that his retirement will be the starting point for new adventures in this attractive field.

Go ahead, Jeff! 


\section{Acknowledgments}

The authors are most grateful to three anonymous referees for their helpful comments. Many of the images of stamps have been taken, with permission, from the excellent website of Jeff Miller [31]; see also the Reinhardt website [32] and the beautiful book by Robin Wilson [33]. For biographical material the authors consulted Abbott [34], Crystal [9], Heyde and Seneta [12], Johnson and Kotz [35], and Meyer [35], as well as the excellent open-access websites of MacTutor [11] and Wikipedia [4]. For closely related material, please see [8]. Many thanks to Evelyn Matheson Styan for her help; she also joins the authors in wishing Jeff a very happy retirement. This research has been supported in part by the Natural Sciences and Engineering Research Council of Canada.

\section{References}

[1] J. J. Hunter, Mathematical Techniques of Applied Probability, Volume 1, Discrete Time Models: Basic Theory, Operations Research and Industrial Engineering, Academic Press, New York, NY, USA, 1983.

[2] J. J. Hunter, Mathematical Techniques of Applied Probability, Volume 2, Discrete Time Models: Techniques and Applications, Operations Research and Industrial Engineering, Academic Press, New York, NY, USA, 1983.

[3] J. J. Hunter, "Characterizations of generalized inverses associated with Markovian kernels," Linear Algebra and Its Applications, vol. 102, pp. 121-142, 1988.

[4] G. P. H. Styan, Ed., "IMAGE philatelic corner [Takakazu Seki Kôwa]," IMAGE: The Bulletin of the International Linear Algebra Society, no. 23, p. 28, 1999.

[5] J. Bernoulli, Ars Conjectandi, Thurnisiorum, Basel, Switzerland, 1713.

[6] R. W. Farebrother, G. P. H. Styan, and G. J. Tee, "Gottfried Wilhelm von Leibniz: 1646-1716," IMAGE: The Bulletin of the International Linear Algebra Society, no. 30, pp. 13-16, 2003.

[7] J. Reinhardt, "Physics-related stamps," June 2007, http://th.physik.uni-frankfurt.de/ jr/physstamps.html.

[8] A. J. Scott and G. P. H. Styan, "On a separation theorem for generalized eigenvalues and a problem in the analysis of sample surveys," Linear Algebra and Its Applications, vol. 70, pp. 209-224, 1985.

[9] D. Crystal, The Cambridge Biographical Encyclopedia, Cambridge University Press, Cambridge, UK, 1994.

[10] P. J. Davis, The Thread: A Mathematical Yarn, Harcourt, Boston, Mass, USA, 2nd edition, 1989.

[11] C. Meyer, Matrix Analysis and Applied Linear Algebra, SIAM, Philadelphia, Pa, USA, 2000.

[12] C. C. Heyde and E. Seneta, Eds., Statisticians of the Centuries, Springer, New York, NY, USA, 2001.

[13] L. Euler, “On magic squares," http://arxiv.org/pdf/math/0408230 (English) .

[14] L. Euler, "De quadratis magicis [On magic squares]," Commentationes Arithmeticae, vol. 2, pp. 593-602, 1849, (Latin).

[15] L. Euler, Opera Omnia, Series 1: Opera Mathematica, vol. 7, Birkhäuser, Boston, Mass, USA, 1992.

[16] J. Grala, A. Markiewicz, and G. P. H. Styan, “Tadeusz Banachiewicz: 1882-1954,” IMAGE: The Bulletin of the International Linear Algebra Society, no. 25, p. 24, 2000.

[17] Wikipedia, “The Free Encyclopedia," http://en.wikipedia.org/.

[18] L.-K. Hua, "Inequalities involving determinants," Acta Mathematica Sinica, vol. 5, pp. 463-470, 1955 (Chinese).

[19] J. J. Hunter, "Generalized inverses and their application to applied probability problems," Linear Algebra and Its Applications, vol. 45, pp. 157-198, 1982. 
[20] A. Ben-Israel and T. N. E. Greville, Generalized Inverses: Theory and Applications, vol. 15 of CMS Books in Mathematics, Springer, New York, NY, USA, 2nd edition, 2003.

[21] C. C. Paige, G. P. H. Styan, B.-Y. Wang, and F. Zhang, "Hua's matrix inequality and Schur complements," International Journal of Information and System Sciences, vol. 4, no. 1, 2008.

[22] R. W. Farebrother, S. T. Jensen, and G. P. H. Styan, "Sir Thomas Muir and nineteenth-century books on determinants," IMAGE: The Bulletin of the International Linear Algebra Society, no. 28, pp. 6-15, 2002.

[23] R. W. Farebrother, S. T. Jensen, and G. P. H. Styan, "Charles Lutwidge Dodgson: a biographical and philatelic note," IMAGE: The Bulletin of the International Linear Algebra Society, no. 25, pp. 22-23, 2000.

[24] C. L. Dodgson, "Condensation of determinants: being a new and brief method for computing their arithmetical values," Proceedings of the Royal Society of London, vol. 15, no. 84, pp. 150-155, 1866.

[25] C. L. Dodgson, An Elementary Treatise on Determinants, with Their Application to Simultaneous Linear Equations and Algebraical Geometry, Macmillan, London, UK, 1867.

[26] L. Carroll, Alice's Adventures in Wonderland \& through the Looking-Glass. With an Introduction by Martin Gardner, Signet Classics, New York, NY, USA, Reissue edition, 2000.

[27] H. Halberstam, "Loo-Keng Hua: obituary," Acta Arithmetica, vol. 51, no. 2, pp. 99-117, 1988.

[28] H. Halberstam, Ed., Loo-Keng Hua Selected Papers, Springer, New York, NY, USA, 1983.

[29] J. Miller, "Images of Mathematicians on Postage Stamps," June 2007, http://jeff560.tripod.com/.

[30] L.-K. Hua, "Inequalities involving determinants," Translations of the American Mathematical Society, Series II, vol. 32, pp. 265-272, 1963 (English).

[31] J. E. Kloetzel, Ed., Scott 2007 Standard Postage Stamp Catalogue, Scott, Sidney, Ohio, USA, 163rd edition, 2006, on paper in 6 volumes and on 12 CD-ROMs with text-searchable pdf files.

[32] J. J. O'Connor and E. F. Robertson, “The MacTutor History of Mathematics Archive," April 2007, http://www-history.mcs.st-andrews.ac.uk/history/index.html.

[33] G. P. H. Styan and G. Trenkler, "IMAGE philatelic corner reprise," IMAGE: The Bulletin of the International Linear Algebra Society, vol. 38, pp. 9-12, 2007.

[34] D. Abbott, Ed., The Biographical Dictionary of Scientists: Mathematicians, Blond Educational, London, UK, 1985.

[35] N. L. Johnson and S. Kotz, Eds., Leading Personalities in Statistical Sciences: From the Seventeenth Century to the Present, Wiley Series in Probability and Statistics: Probability and Statistics, John Wiley \& Sons, New York, NY, USA, 1997.

George P. H. Styan: Department of Mathematics and Statistics, McGill University, 805 Ouest, Rue Sherbrooke, Montréal, Québec, Canada H3A 2K6

Email address: styan@math.mcgill.ca

Götz Trenkler: Fachbereich Statistik, Universität Dortmund, 44221 Dortmund, Germany

Email address: trenkler@statistik.uni-dortmund.de 


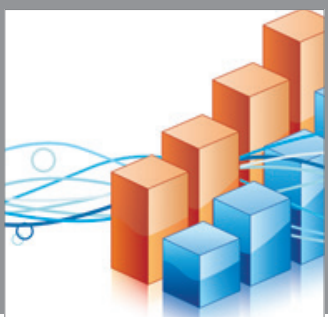

Advances in

Operations Research

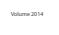

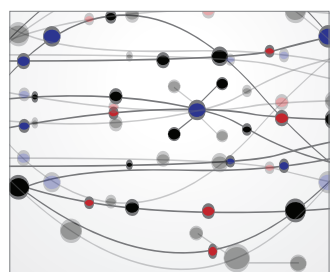

\section{The Scientific} World Journal
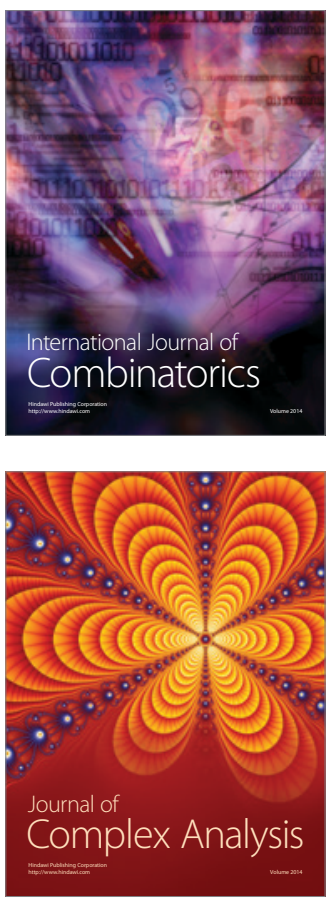

International Journal of

Mathematics and

Mathematical

Sciences
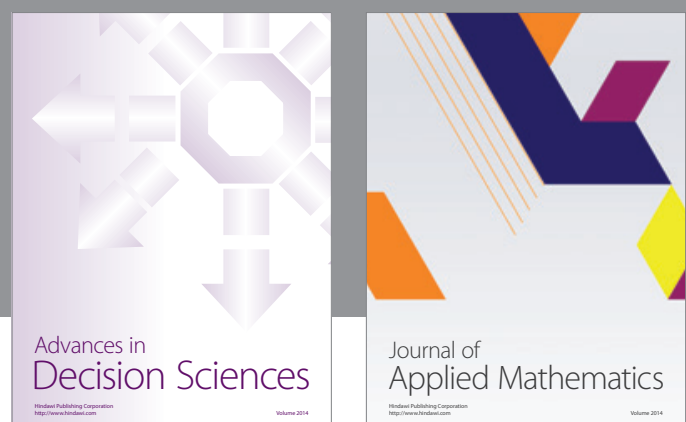

Journal of

Applied Mathematics
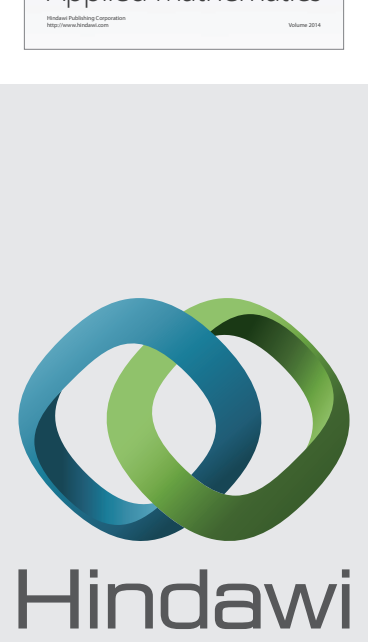

Submit your manuscripts at http://www.hindawi.com
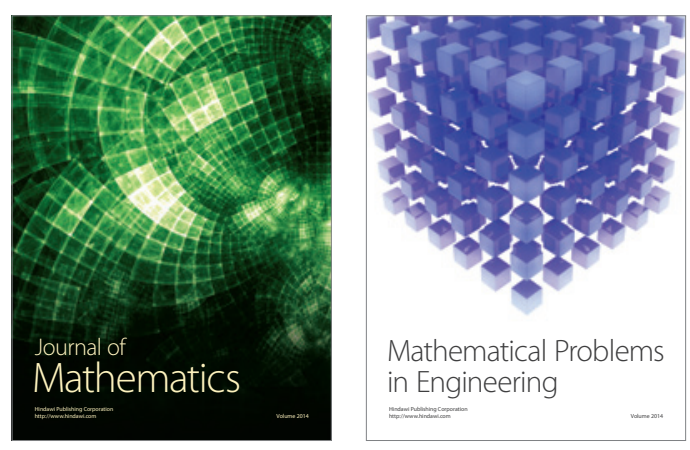

Mathematical Problems in Engineering
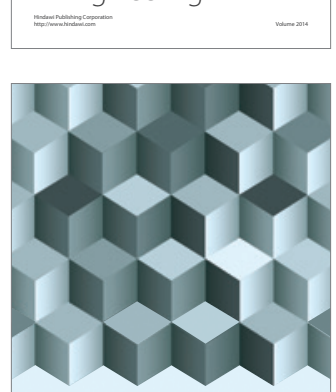

Journal of

Function Spaces
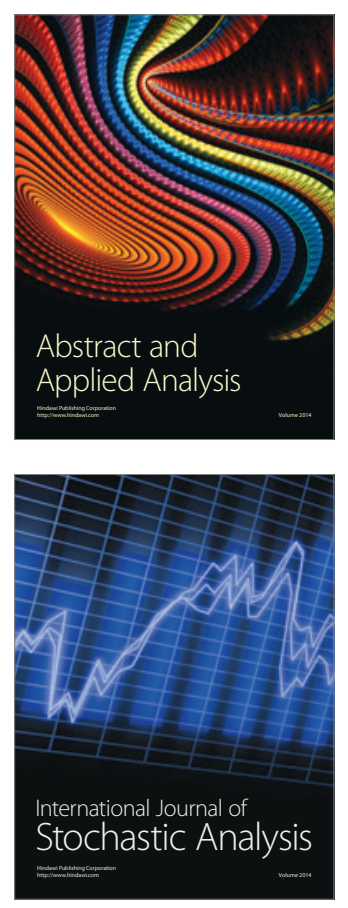

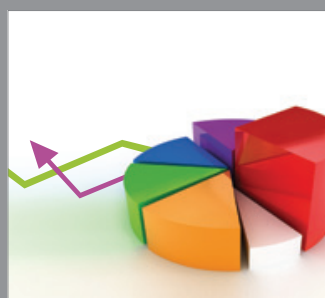

ournal of

Probability and Statistics

Promensencen
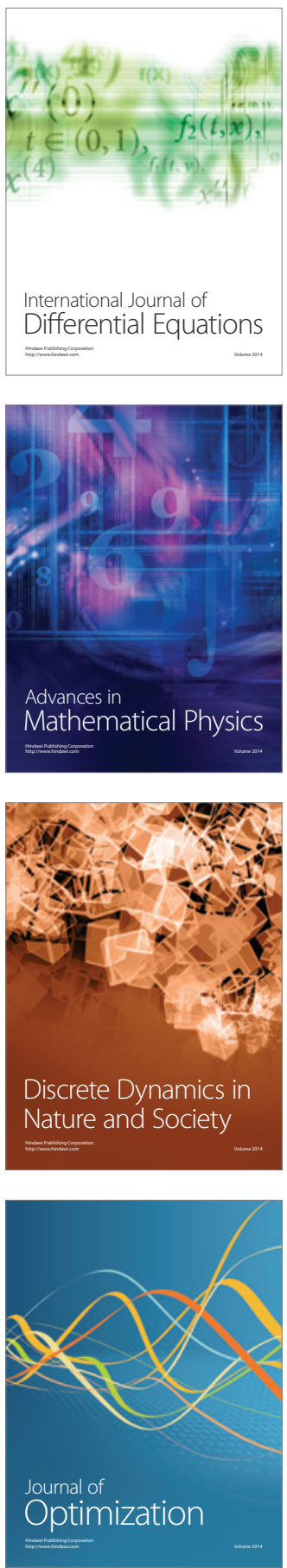